1352-2310(95)00180-8

\title{
THE STEAM-JET AEROSOL COLLECTOR
}

\author{
A. KHLYSTOV, G. P. WYERS and J. SLANINA \\ Netherlands Energy Research Foundation, ECN, P.O. Box 1, 1755 ZG Petten, The Netherlands
}

(First received 3 November 1994 and in final form 6 April 1995)

\begin{abstract}
A new principle of sampling aerosol particles by means of steam injection with the consequent collection of grown droplets has been established. An air stream free of water-soluble gases is rapidly mixed with steam. The resulting supersaturation causes aerosol particles to grow into droplets. The droplets containing dissolved aerosol species are then collected by two cyclones in series. The solution collected in the cyclones is constantly pumped out and can be on- or off-line analysed by means of ion chromatography or flow injection analysis. On the basis of the new sampling principle a prototype of an aerosol sampler was designed which is capable of sampling particles quantitatively down to several nanometres in diameter. The mass sampling efficiency of the instrument was found to be $99 \%$. The detection limit of the sampler for ammonium, sulphate, nitrate and chloride ions is below $0.7 \mu \mathrm{g} \mathrm{m}^{-3}$. By reduction of an already identified source of contamination, much lower detection limits can be achieved. During measurements the sampler proved to be stable, working without any assistance for extended periods of time. Comparison of the sampler with filter packs during measurements of ambient air aerosols showed that the sampler gives good results.
\end{abstract}

Key word index: Aerosol, sampling.

\section{INTRODUCTION}

A better insight into the transport processes of atmospheric aerosols is needed to improve our understanding of the adverse effects of air pollution due to aerosols. Aerosols contribute to acidification and eutrophication of land and water resources via wet and dry deposition (Fowler et al., 1992). Recent analysis of the radiative effects of aerosols suggest that aerosols may have a significant impact on climate (Charlson et al., 1992). Aerosol particles affect the earth's radiative balance by back-scattering and absorption of solar radiation such that the earth's surface receives less radiation. In an indirect way aerosol particles also act as cooling agents by increasing albedo and lifetime of shallow marine clouds (Charlson et al., 1991; Twomey, 1991).

The fundamental aerosol properties most relevant to environmental issues are the particle size distribution and chemical composition. Consequently, measurements of chemical composition of aerosol are of considerable importance. Furthermore, measurements of temporal and spatial changes in the relative concentrations of different species in aerosol can give considerable insight into the origin of particles. At the moment aerosols are mostly sampled by "batch" techniques like filter packs and impactors, which are very labour intensive and do not allow on-line analysis. Thermodenuders have been developed for automatic measurement of concentrations of e.g. ammonium nitrate and ammonium sulphates (Slanina et al., 1992).

Here we describe a sampler for collecting aerosols behind a wet denuder system. The sampler has a simple design and allows on-line analysis of aerosols for four major ionic species: $\mathrm{NH}_{3}^{+}, \mathrm{SO}_{4}^{2-}, \mathrm{NO}_{3}^{-}$and $\mathrm{Cl}^{-}$.

\section{GENERAL DESCRIPTION AND WORKING CONDITIONS}

A general scheme of the steam-jet aerosol collector (SJAC) is given in Fig. 1. The system consists of the following parts:

(1) mixing reservoir;

(2) steam generator;

(3) two cyclones in series;

(4) condenser;

(5) pump.

An air stream free of water-soluble gases after passage through a wet denuder (Keuken et al., 1988) is rapidly mixed with steam coming from the steam generator. The resulting supersaturation causes aerosol particles to grow into droplets of at least $1 \mu \mathrm{m}$ diameter. These droplets containing dissolved aerosol species are then collected by two cyclones in series. The solution collected in the cyclones is constantly pumped out with a peristaltic pump and can be on- or off-line analysed 


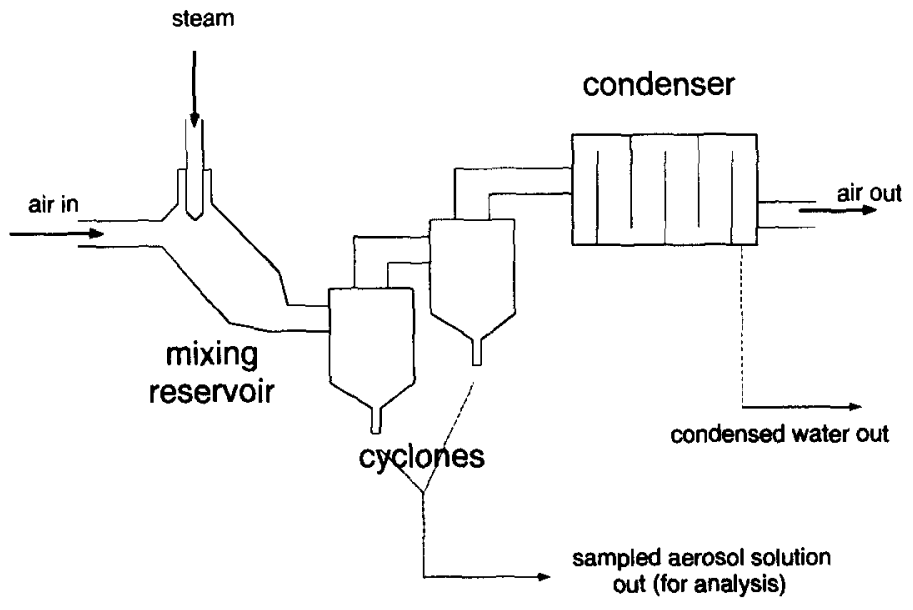

Fig. 1. General scheme of the steam-jet aerosol collector.

by means of ion chromatography (IC) or flow-injection analysis (FIA).

The steam generator is a three-neck flask placed into an electrical heating mantle. Doubly demineralized water is constantly pumped in through one of the necks. Through another neck steam is led into the mixing reservoir via a heated glass tube. The steam output of the generator depends on the oven temperature. The temperature in the generator is higher than $100^{\circ} \mathrm{C}$, because steam is injected through a critical orifice for $5 \ell \mathrm{min}^{-1}$, which causes the generator to be at an overpressure (more than $100 \mathrm{~cm}$ of water). The critical orifice is used for the following reasons. Steam leaves the nozzle as a strong jet which breaks through the main air stream and causes very strong turbulence inside the reservoir. The high turbulence provides the necessary fast mixing of steam with the air stream such that the air is supersaturated before most of the water is lost on the walls. The second reason is that water in the generator is boiling at a higher than atmospheric pressure. Consequently, more water is injected per unit time. In addition, adiabatic cooling of the jet can perhaps play some role in establishing the supersaturation. To avoid condensation, the tube connecting the flask with the mixing reservoir is heated with a heating tape so that its temperature is equal to the temperature in the generator.

The optimum oven temperature was found to be approximately $105^{\circ} \mathrm{C}$, which corresponds to steam injection of $3.5 \mathrm{~g}$ of water per minute. As will be shown later, this rate of steam injection lies within the range theoretically expected to give maximum supersaturation.

The mixing reservoir represents a two-neck glass tube of $40 \mathrm{~cm}^{3}$ volume, tapered at the end. The tube is fixed in such a way that the inlet is horizontal and steam is injected vertically from the top (see Fig. 1). The main axis of the mixing reservoir is approxim- ately at $45^{\circ}$ to the horizontal, allowing condensed water to flow down into the cyclone. The residence time of the air-steam mixture in the reservoir is approximately $0.1 \mathrm{~s}$.

The cyclones are made of high-density polyethylene. The $50 \%$ cut-off diameter of the cyclones at $22.5 \ell \min ^{-1}$ is less than $1 \mu \mathrm{m}$. The cyclones are placed vertically, one after another. The solution collected in the cyclones is constantly pumped out by means of a peristaltic pump. Approximately $0.6 \mathrm{ml}$ of solution per minute is collected in the cyclones.

The condenser is used to reduce the amount of steam entering the pump and to reduce the influence of ambient temperature fluctuations on the flow rate into the sampler. It is a glass vessel $(\sim 2 \ell)$ with a large surface area cooled by a small ventilator. Condensed water is constantly pumped out by means of a peristaltic pump.

Air is drawn into the system by a pump equipped with a critical orifice for $30 \ell \mathrm{min}^{-1}$. The actual flow rate into the sampler is $22.5 \ell \mathrm{min}^{-1}$ because of the additional steam flow and thermal expansion.

\section{BRIEF THEORETICAL CONSIDERATION}

Most inorganic salts exhibit deliquescence upon exposure to moisture. Deliquescence is the rapid phase transition from a solid particle to a liquid drop, which occurs only when the relative humidity reaches a certain critical value corresponding to the water activity of the saturated solution.

As soon as deliquescence occurs, a particle will take up water according to the saturation of the atmosphere with water vapour and grow to a certain equilibrium size. The growth rate is reciprocal to the droplet radius and is proportional to the difference between the vapour pressure above the drop surface and the vapour pressure of the environment (Prup- 


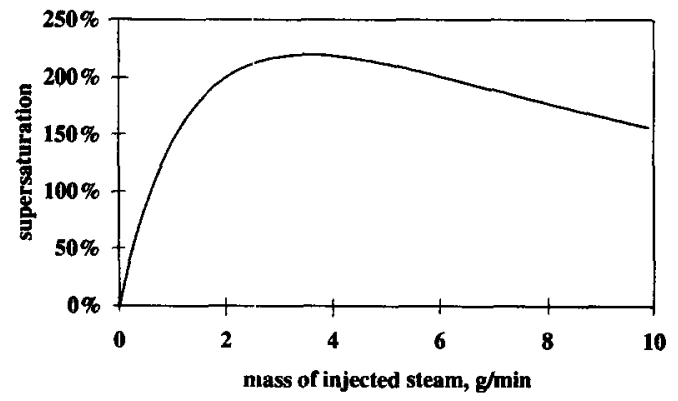

Fig. 2. Supersaturation in the sampler as a function of injected steam mass.

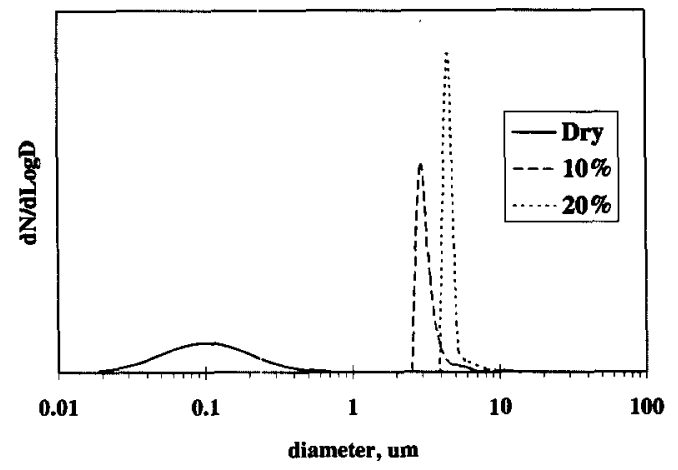

Fig. 3. Droplet spectra after $0.1 \mathrm{~s}$ growth at 10 and $20 \%$ supersaturation.

pacher and Klett, 1978). Consequently, the higher the relative humidity of the environment, the faster a droplet will grow.

In the sampler the air stream is strongly supersaturated with water by injection of steam. If we assume that most of the supersaturation in the system arises from the mixing of two saturated parcels with different temperatures, the resulting supersaturation in the sampler can be easily calculated from the energy balance. Calculations indicate that the maximum supersaturation in the system is $200-250 \%$ (Fig. 2). These values are achieved when $3-4 \mathrm{~g}$ of water vapour are injected per minute into the air stream of $22.5 \ell \mathrm{min}^{-1}$. This injection rate of steam is in good agreement with that experimentally found to be optimal.

In reality, the mixing process in the sampler is far from ideal. There is a competition between condensation on aerosol particles and condensation on the walls. Approximately $50 \%$ of the water vapour is condensed on the walls of the mixing reservoir. The temperature of the resulting mixture is increasing due to the release of latent heat. All these processes reduce the resulting supersaturation. However, our calculations show that even if we assume that the supersaturation is only $10 \%$, the residence time inside the mixing reservoir $(\sim 0.1 \mathrm{~s})$ is still sufficient for particles

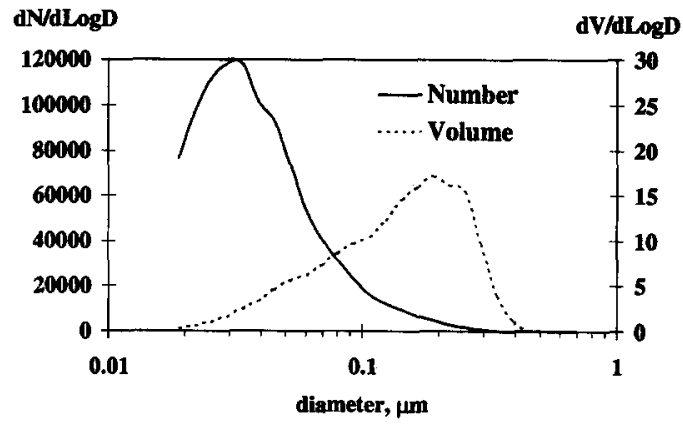

Fig. 4. Number and mass distributions of model ammonium sulphate aerosol.

Table 1. Blank concentrations of the four major ions in the sampler

\begin{tabular}{lcccc}
\hline & $\begin{array}{c}\mathrm{NH}_{4}^{+} \\
\left(\mu \mathrm{g} \mathrm{g}^{-1}\right)\end{array}$ & $\begin{array}{c}\mathrm{SO}_{4}^{2-} \\
\left(\mu \mathrm{g} \mathrm{g}^{-1}\right)\end{array}$ & $\begin{array}{c}\mathrm{NO}_{3}^{-} \\
\left(\mu \mathrm{g} \mathrm{g}^{-1}\right)\end{array}$ & $\begin{array}{c}\mathrm{Cl}^{-} \\
\left(\mu \mathrm{g} \mathrm{g}^{-1}\right)\end{array}$ \\
\hline Concentration & 0.014 & 0.023 & 0.016 & 0.014 \\
STD & 0.001 & 0.008 & 0.005 & 0.006 \\
\hline
\end{tabular}

down to $19 \mathrm{~nm}$ dry diameter to grow up to $1 \mu \mathrm{m}$ droplets which can be collected by the cyclones (Fig. 3), which testifies the possibility to quantitatively collect hygroscopic aerosol particles in the sampler.

\section{SAMPLING EFFICIENCY DETERMINATIONS}

\section{The model aerosol}

The sampling efficiency of the sampler was determined in two ways: with a back-up filter and with a DMPS (Differential Mobility Particle Sizer, TSI Model 3932). Ammonium sulphate aerosol was used as a model aerosol for these experiments. The aerosol was generated by spraying $0.316 \mathrm{~g} \ell^{-1}$ ammonium sulphate solution with a Wright's nebulizer. The flow of droplet-laden air from the nebulizer $\left(10 \ell \mathrm{min}^{-1}\right)$ was mixed with the flow $\left(20 \ell \mathrm{min}^{-1}\right)$ of dry purified air. To avoid interferences of ambient gases and aerosols both nebulizing and drying air flows were purified before entering the generator by means of a gas adsorption column and filters. Moving through a glass tube (length $2.5 \mathrm{~m}$, diameter $5 \mathrm{~cm}$ ) the droplets are dried to form salt particles. The number and the mass size distributions of the aerosol were measured with the DMPS. The number and mass distributions of the aerosol are given in Fig. 4. The number geometrical mean diameter lies in the range $0.038-0.039 \mu \mathrm{m}$ and the volume geometrical mean diameter is in the range $0.133-0.135 \mu \mathrm{m}$. The number concentration of the generated aerosol was rather high, approximately $60,000 \mathrm{~cm}^{-3}$, but for our purpose it was not of importance, as the higher the number concentration is, the more difficult it is to induce growth of all droplets to the required size. 
Measurements of the blank concentrations in the sampler

The blank of the sampler was determined in the following way. The system was cleaned thoroughly. Clean air was brought in excess to the inlet of the sampler through a filter pack (PTFE, NaF-coated and $\mathrm{H}_{3} \mathrm{PO}_{4}$-coated filters). The steam injection was on and the air was pumped through the sampler during $3 \mathrm{~h}$. Table 1 gives the blank concentrations of $\mathrm{NH}_{4}^{+}$, $\mathrm{SO}_{4}^{2-}, \mathrm{NO}_{3}^{-}$and $\mathrm{Cl}^{-}$.

The main source of the blank was found to be a residual contamination on the walls of the steam sampler. As aerosols in $22.5 \ell$ of air are dissolved in $0.6 \mathrm{~g}$ of water (or aerosols in $1 \mathrm{~m}^{3}$ are dissolved in $26.6 \mathrm{~g}$ of water) we can find the detection limit of the sampler from the threefold noise of the blank. The resulting detection limits for $\mathrm{NH}_{4}^{+}, \mathrm{SO}_{4}^{2-}, \mathrm{NO}_{3}^{-}$and $\mathrm{Cl}^{-}$in air are $0.08,0.64,0.40$ and $0.48 \mu \mathrm{g} \mathrm{m}^{-3}$, respectively. By eliminating the contamination from the steam generator the detection limit will be reduced considerably.

\section{Measurements of the sampling efficiency with a back-up filter}

To determine the mass sampling efficiency of the instrument a filter was placed between the last cyclone and the condenser. QM-A filters were used as back-up filters as they have a low pressure drop and are not easily clogged by water. To avoid condensation on the filter, the filter holder and the tube connecting the cyclone with the filter holder were slightly heated by means of a heating tape. After sampling the filters were rinsed in $7 \mathrm{ml}$ of doubly demineralized water and the obtained solution was consequently analysed by means of IC.

The sampling efficiency was determined as the ratio of the aerosol mass collected by the sampler to the mass collected both in the sampler and on the backup filter. During initial experiments with a single cyclone the mass sampling efficiency of the sampler was $90 \%$. The use of two cyclones in series increased the sampling efficiency considerably. With two cyclones the efficiency was found to be better than $99 \%$. Possibly, the first cyclone is overloaded with condensed water coming from the mixing reservoir, such that some of the solution escapes into the exhaust and is collected in the second cyclone.

\section{Measurements of the sampling efficiency with the DMPS}

The DMPS was used to determine the sampling efficiency and to find out to which size particles are sampled in the system. The tube from the last cyclone was split into two, the angle between them being $30^{\circ}$. One of the tubes was connected to the pump, the other was connected to the DMPS through a diffusion dryer. The tube leading to the dryer was heated with a heating tape. The purpose of the dryer was to reduce the humidity of the air flow into the DMPS and to dry the droplets which were not collected by the cyclones. The aerosol which comes into the DMPS has two origins:

(1) from aerosol particles that have not started to grow into droplets;

(2) from the salt content of uncollected droplets.

The sampling efficiency was determined from comparisons of the size spectra found with and without steam injection. To find the optimum temperature for steam generation, the spectra were recorded at different oven temperatures. The number comparisons of size spectra are given in Fig. 5. The steam injection rate of $3.5 \mathrm{~g} \mathrm{~min}^{-1}$ was found to be optimal as the number concentration in every channel does not exceed $0.12 \%$ of the concentration without steam injection. We can conclude that the sampler collects more than $99 \%$ of the total aerosol number in the size range $0.019-0.886 \mu \mathrm{m}$, which is in good agreement with the filter measurements. The optimum steam injection

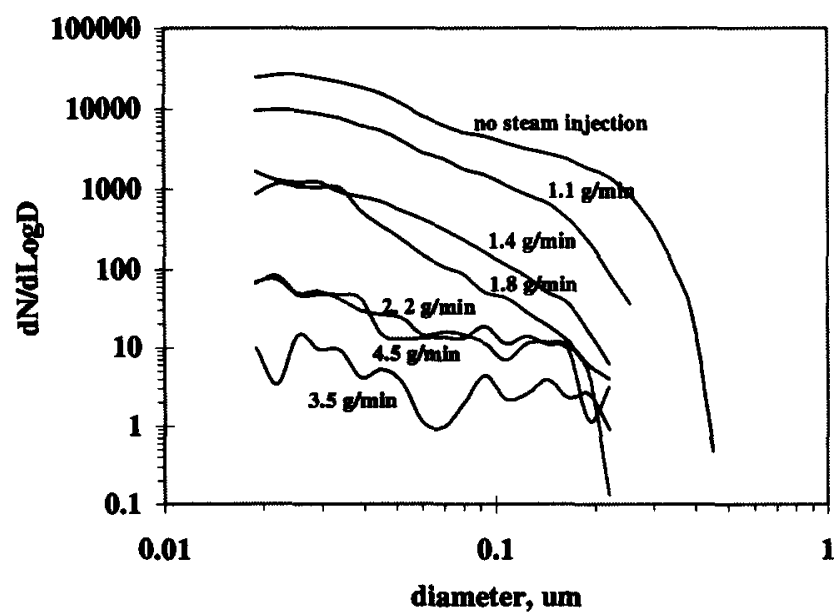

Fig. 5. Comparison of number size distributions of model ammonium sulphate aerosol at different steam injection rates. 
rate is also in good agreement with the theoretically found values (Fig. 2).

\section{COMPARISON MEASUREMENTS}

Several comparison measurements of ambient air aerosols were done at ECN (Petten, The Netherlands). During the measurements the sampler was compared with filter packs. Two wet denuders were placed in front of the sampler to remove water-soluble gases. The first was a denuder with a carbonate solution for sampling acidic species, the second contained formic acid for sampling ammonia. The filter packs consisted of a Teflon filter, $\mathrm{NaF}$ - and $\mathrm{H}_{3} \mathrm{PO}_{4}$-coated filters. Two dry annular denuders ( $\mathrm{NaF}$ - and $\mathrm{H}_{3} \mathrm{PO}_{4}$-coated) were used in front of the filter packs to avoid inter-

Table 2. Comparison measurements "wet denuders-aerosol sampler" (SJAC)/annular denuder-filter pack" (FP)

\begin{tabular}{|c|c|c|c|c|c|c|c|c|}
\hline \multirow[b]{2}{*}{ Date } & \multicolumn{2}{|c|}{$\mathrm{NH}_{4}^{+}$} & \multicolumn{2}{|c|}{$\mathrm{SO}_{4}^{2-}$} & \multicolumn{2}{|c|}{$\mathrm{NO}_{3}^{-}$} & \multicolumn{2}{|c|}{$\mathrm{Cl}^{-}$} \\
\hline & SJAC & FP & SJAC & FP & SJAC & FP & SJAC & FP \\
\hline \multirow{3}{*}{$\begin{array}{l}10 \text { September } 92 \\
11 \text { September } 92\end{array}$} & 4.66 & 2.96 & 4.25 & 4.59 & 9.09 & 5.65 & 0.36 & 0.08 \\
\hline & 4.69 & 4.31 & 4.68 & 4.68 & 7.89 & 7.10 & 0.60 & 0.65 \\
\hline & 1.92 & 2.02 & 3.09 & 3.19 & 2.62 & 2.33 & 1.98 & 2.97 \\
\hline \multirow[t]{4}{*}{ 17-18 September: 92} & 2.15 & 2.29 & 1.67 & 1.69 & 5.72 & 5.23 & 2.42 & 1.72 \\
\hline & 6.34 & 5.97 & 5.03 & 5.52 & 10.73 & 10.82 & 0.67 & 0.83 \\
\hline & 7.46 & 7.05 & 5.83 & 6.30 & 14.55 & 13.28 & 0.77 & 1.09 \\
\hline & 10.25 & 10.06 & 8.40 & 8.24 & 18.86 & 21.07 & 1.67 & 2.38 \\
\hline \multirow{2}{*}{27 September 92} & 1.75 & 2.19 & 4.07 & 3.83 & 1.77 & 2.08 & 1.86 & 3.05 \\
\hline & 1.77 & 2.28 & 3.12 & 2.95 & 2.05 & 2.64 & 1.14 & 2.69 \\
\hline
\end{tabular}
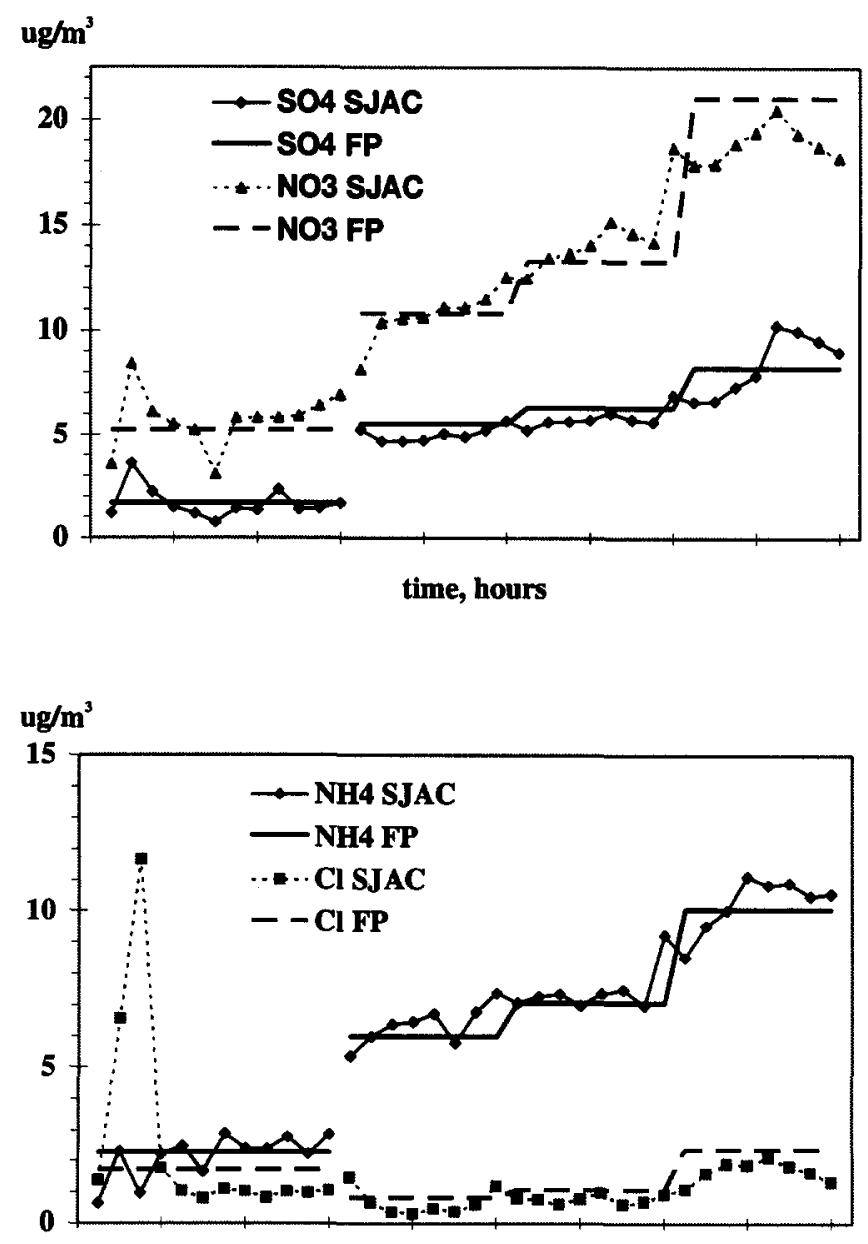

time, hours

Fig. 6. Comparison of the sampler (SJAC) with filter pack (FP) measurements of ambient aerosol on 17-18 September 1992. 
ferences by gaseous compounds. The filters sampled for $2 \mathrm{~h}$ each. The flow through the filters was measured by means of a gas meter. The inlets of both systems were put next to each other.

The results of the measurements are summarized in Table 2. On 10 September the concentrations of $\mathrm{NH}_{4}^{+}$ and $\mathrm{NO}_{3}^{-}$were almost two times higher in the sampler than in the filter pack. The difference can be explained by losses of large ammonium nitrate particles in the dry annular denuders. The experiments of $11,17,18$ and 27 September gave very good comparison results. Figure 6 shows the comparison on 17 and 18 September.

\section{CONCLUSIONS}

This study indicates that the principle of sampling aerosol particles by means of steam injection with the consequent collection of grown droplets is a sound method. The sampler itself is quite simple, relatively small and portable. During continuous measurements the sampler proved to be stable, working without any assistance during extended periods of time. The mass sampling efficiency of the instrument was found to be $99 \%$. The sampler is capable of sampling particles quantitatively down to several nanometres in diameter. The detection limit for $\mathrm{NH}_{4}^{+}, \mathrm{SO}_{4}^{2-}, \mathrm{NO}_{3}^{-}$and $\mathrm{Cl}^{-}$, found as threefold noise of the blank, is $0.08,0.64$, 0.40 and $0.48 \mu \mathrm{g} \mathrm{m}^{-3}$, respectively. When contamination from the steam generator can be reduced, much lower detection limits for $\mathrm{SO}_{4}^{2-}, \mathrm{NO}_{3}^{-}$and $\mathrm{Cl}^{-}$can be achieved. Comparison of the sampler with filter packs during measurements of outdoor aerosols showed that the sampler gives good results.

Acknowledgements-We thank Beate Arends, Rene Otjes and Anita Waijers for their help in developing this sampling technique. We also wish to express gratitude to Harry ten Brink for useful discussions and assistance with DMPS measurements.

\section{REFERENCES}

Charlson R., Schwartz S. E., Hales J. M., Cess R. D., Coackley Jr J. A., Hansen J. E. and Hofmann D. J. (1992) Climate forcing by anthropogenic aerosols. Science 25, 423-430.

Charlson R., Langner J., Rodhe H., Levoy C. B. and Warren S. G. (1991) Perturbation of the Northern Hemisphere radiative balance by backscattering from anthropogenic sulphate aerosols. Tellus 43AB, 152-163.

Fowler D., Cape J. N., Sutton M. A., Mourne R., Hargreaves K. J., Duyzer J. H. and Gallagher M. W. (1992) Deposition of acidifying compounds. In Acidification Research: Evaluation and Policy Applications. Proc. Int. Conf., Maastricht, The Netherlands, 14-18 October 1991, pp. 553-572. Elsevier, Amsterdam.

Keuken M. P., Schoonebeek C. A. M., van Wensveen-Louter A. and Slanina J. (1988) Simultaneous sampling of $\mathrm{NH}_{3}$, $\mathrm{HNO}_{3}, \mathrm{HCl}, \mathrm{SO}_{2}$ and $\mathrm{H}_{2} \mathrm{O}_{2}$ in ambient air by wet annular denuder system. Atmospheric Environment 22, 2541-2548.

Pruppacher H. R. and Klett J. D. (1978) Microphysics of Cloud and Precipitation. Reidel, Dordrecht.

Slanina J., de Wild P. J. and Wyers G. P. (1992) The application of denuder systems to the analysis of atmospheric components. In Gaseous Pollutants: Characterization and Cycling (edited by Nriagu J. O.), pp. 129-154. Wiley, New York.

Twomey S. (1991) Aerosols, clouds and radiation. Atmospheric Environment 25A, 2435-2442. 